\title{
The Gurkhas and Great Inequalities in Their Lives
}

\author{
Xiaoyu $\mathrm{Wu}^{1} \&$ Kui $\mathrm{Zhu}^{2}$ \\ ${ }^{1}$ University of Queensland, Australia \\ ${ }^{2}$ Sichuan Agricultural University, People's Republic of China \\ Correspondence: Kui Zhu. E-mail: zk7660@126.com
}

Received: June 28, 2017

Accepted: July 26, 2017

Online Published: August 25, 2017

doi:10.5539/ass.v13n9p119

URL: https://doi.org/10.5539/ass.v13n9p119

\begin{abstract}
The Nepalese Gurkhas have been in military service for the British more than 200 years and played an important role not only in helping the British exert its control over its colonials or protectorates, but also in securing some countries or keeping the world peace. However, these Gurkhas have not enjoyed their rights because of their unique identity. Therefore, this paper begins with the history of the Gurkha regiment, the martial race theory as well as the racist ideas on the Gurkhas. Then it turns to the great inequalities that the Gurkhas have experienced during their military service and after their retirement as well as in law \& British court. Finally, it briefly covers reasons for Gurkhas' inequalities and ways to eliminate the inequalities.
\end{abstract}

Keywords: Gurkhas; martial race theory; inequalities; discrimination; colonial logics

\section{Introduction}

In the colonies like India, there was a special relationship among the colonial administration, state violence, and imperial power. During the British administration, the Indian army was selected as a violence force to help rule India, but to some extent, it was also a potential threat to the British administration since they might participate in uprisings, which would interfere with the normal governance in turn, and the uprising in 1857 was a good case in point. Therefore, it was significant for the British administrators in India to own a legion that would be both good at fighting and loyal to the Crown Colony. And the Gurkha regiment was made such a legion and has become an integral part of the British army. They have been loyal and brave enough to work for the UK, and there are still many Gurkha soldiers in British army today. Nevertheless, their work has not earned them corresponding respect and basic rights in pay, pensions or settlement, etc. Hence, we try to discuss the inequalities that the Gurkhas have experienced during their military service and after their retirement as well as in law \& British court after a brief review of the history of the Gurkha regiment, the martial race theory as well as the racist ideas on the Gurkhas. Finally, we briefly analyze reasons for Gurkhas' inequalities and suggest ways to change this situation.

\section{The Gurkhas and the Martial Race Theory}

\subsection{A brief history of the Gurkhas}

When people talk about the ethno-racial term 'Gurkha', they specifically refer to those Nepalese soldiers in the foreign military service. In fact, this term is not accurate; it was originally Gorkha, which is a place in Nepal, located in the West of the capital Gaddeau. But western people mispronounced Gorkha as 'Gurkha' and this very 'Gurkha' was gradually accepted. Gurkha was a warrior place and its people continually marched into battles for the unity of Nepal, thus making a group of Gurkhas, who were brave and skillful in battle. These Gurkhas were recruited to serve the British army in India in the 18th century, for at that time the British colonial administrators found that the ethno-linguistic and religious diversity as well as the highly developed civilizations in Indian sub-continent created a lot of challenges for their continuous and justified governance on India and its people based on the racial and cultural superiority. To meet the challenges, a large number of British anthropologists and ethnographers were sent to the colony to 'document' the distinctions and diversities of the local people (Kuklick, 1991, cited in Kochhar-George, 2010:45). With the efforts of the scholars, they finally wrote out lots of literatures concentrating on the classification and categorization of those people. Therefore, the British colonial administrators could make policies of divide-and-rule on the basis of race, religion, caste and ethnicity with the help of these literatures (Mahmud, 1999, cited in Kochhar-George, 2010:45). Along with the British empire, the Gurkha was considered as a group 'for the benefit of British military expedience rather than as a discrete ethnic 
group' (Caplan, 1995, cited in Kochhar-George, 2010:45) though in modern sense the Gurkha 'has firmly become part of popular military parlance and can be viewed as a by-product of the imperialist project of justifying and enforcing colonial rule'(Mahmud, 1999, cited in Kochhar-George 2010:45).

The Anglo-Nepalese War (1814-16) provided an opportunity for the Gurkhas to show themselves on the international military stage. In 1814, the Britain declared war on the Kingdom of Nepal with the excuse of the border issue. During the war, the Kingdom of Nepal sent 12,000 Gurkha soldiers to assault the British soldiers stationed in Kashmir and Bhutan. Although the British forces were twice as much as the Gurkhas soldiers, they were once defeated by the Gurkhas, and these Gurkha soldiers stroke the British commanders as the brave and brilliant. However, in March 1816, Nepal was defeated due to the limited numbers of the troops and poor weapons, and was forced to sign the Treaty of Sugauli with Britain, which ceded about a third of Nepal's territory to the British and permitted the British to recruit the Gurkhas in Nepal. On the other side, the Nepalese were also willing to be recruited as Gurkhas by the British, since they could increase their economic and social capital as well as respect from others (Chisholm, 2014:31).

Though brave and brilliant, the Gurkhas in the British military were first not given important responsibilities. Luckily, this was changed by what happened in 1857 . The year 1857 witnessed uprisings against British colonial administration in India- continuous mutinies and insurrections of the Indian soldiers. It was during this mutiny that Gurkhas solidified their loyalty and bravery amongst British military soldiers and then in order to strengthen the colonial control of India, the British Indian authorities were determined to recruit a large number of Gurkhas into the army, and gradually put more responsibilities on the Gurkhas. Afterwards, the Gurkhas were more loyal to the British: in both World War I and World War II, about 20 million Gurkhas served in the British army, of whom about 45,000 were killed in battles.

After the independence of India, an agreement on the recruitment of Gurkha soldiers was signed among India, Nepal and Britain- Britain continued to enjoy the right to recruit the Gurkhas as regular soldiers in the British army, and India followed the British practice, getting the privilege of recruiting Gurkha soldiers as well. This agreement in 1947 not only brought the Gurkhas to other remaining British Colonies like Malaysia and Singapore but 'provides the basis for employment policies until today' (Uesugi, 2007, cited in Low, 2016:844). In Singapore, the first Gurkha Contingent of the Singapore Police Force was assembled on 9 April 1949(Rai, 2009, cited in Low, 2016:844). In 1958, the British, Nepalese and the New Singapore government reached an agreement, one of whose terms was that the Gurkha Contingent was to be led only by British and Gurkha officers in order to sustain 'political impartiality essential in a paramilitary unit of a police force' (Leathart, 1996, cited in Low, 2016:844). Additionally, Brunei, as a protectorate of the British Empire according to Brunei Constitution in September 1959, put all its foreign relations, defense and security in the hand of the UK, thus involving the Gurkhas in Brunei, 'fighting against guerillas and guarding oil installations' (Dutt, 1981, cited in Low, 2016:845). Briefly speaking, in the past 60 years, the Gurkhas have been fighting in many places of the world. They have been especially involved in almost all of the conflicts related to Britannica or India, including the Indo-Pakistani war, the Sino-Indian border conflict, the Iraq War and the war on terrorism in Afghanistan.

\subsection{Martial race theory}

As is said, the Gurkhas didn't conform to the early martial race theory because they were in small sizes. However, in the first handbook- Eden Vansittart's Notes on Goorkhas (1890), Vansittart explored the history, customs and characteristics of the Nepalese, and concluded that the Gurkhas were also a martial race. Namely, both their Tibeto-Mongolian ancestry and the environmental determinism contributed much to the martiality of the Gurkhas, because in order to live in the harsh Himalayan conditions, they had to form a warlike nature (Golay, 2006:30). According to Mahmud(1999), 'the Gurkhas' hardy warlike nature, so eulogized in reports and dispatches, could therefore be attributed to the hardships of enduring the harsh Himalayan conditions of their homeland, rather than any notions of racial superiority'(cited in Kochhar-George, 2010:47). Briefly, it was their warlike nature that made the Gurkhas known to the West through their military services in the British and Indian militaries and through a process of martial race. They were understood and accepted not because of their individual attributes but because of being grouped together as a 'fierce warrior' race (Vines, 1999, cited in Chisholm, 2014:32).

In 1933, The Martial Races of India written by George MacMunn was published, arguing that there were only certain groups of people in India who could be trained as soldiers. That is to say, the martial race discourse distinguished the Indians from the white people. In the book, the author pointed out that it was important for the martial races to be brave, amenable to disciplines and to obey the orders. It means that the martial race discourse has reflected the practical requirement of the recruitment- the British needed more soldiers to help rule the 
colony, and the soldiers from the Indian society had to be loyal to the British.

However, there were some negative racist ideas except the praise for their bravery and loyalty. As mentioned above, the Gurkhas had very small physical stature and they were quite unfamiliar with the tactics, so some westerners used the word 'childlike' and 'simple' to imply that they could only show their combat capability under the instruction of the British military experts (Golay, 2006:31). Unfortunately, there were even some other humiliating and racially discriminatory words, such as 'tykes', 'little blighters', 'mountain goats', 'gambolling bull-pups' and 'barbarous bloodthirsty people' (Caplan, 1995, cited in Kochhar-George, 2010:48). To make matters worse, there existed discrimination against the Gurkhas even from the British: they argued that the Gurkhas were quite different in stature and intelligence from the white soldiers, and therefore they had to be put under the command of British officers to achieve their martiality, that is, even with the same stature and intelligence, their abilities are far less than those of white soldiers. And this discrimination has caused the Gurkhas to encounter great inequalities during their lives in and outside the military service.

\section{Inequalities in Gurkhas' Lives}

\subsection{Inequalities during the military service}

To become members of the Gurkhas in British army, the potential Gurkha recruits, who are required to be 17-21 years old, have to pass much more rigorous selection than the British recruits. For example, even at present ' 176 out of around 11,000 Gurkha applicants are selected annually by the British Army' according to the notes of Bellamy (2011, cited in Low, 2016:844). Once they are enlisted, they have to remain the Nepalese citizenship during their military service, because Gorkha was not once a colony of Britain. As for the job prospects, it is hard for the Gurkhas to be promoted as officers during the period of service. According to the statistics, only 150 of them have been officers of the 3,850 Gurkhas currently serving in the British Army, which is just $1 \%$ of the total number of officers in British Army (Kochhar-George, 2010:48). For Gurkhas in Singapore, they comprise 'approximately 1,850 officers (13\% of the total police force)' (Low, 2016:845) though they work as a paramilitary force, securing important facilities in the country and guarding the residences of top politicians. At the same time, the payment for the Gurkhas is not so satisfying, or to say, the payment is actually substantially lower compared with that of the British soldiers. Moreover, the Gurkhas are required to retire after 15 years of service, while the British soldiers can retire after 22 years. And after the retirement, they still receive substantially lower pensions than those of the British. In addition, Gurkhas and their families do not enjoy the same basic right as the citizens where the Gurkhas are stationed. For example, after the Opium War of 1841 Hong Kong was made a colony and Gurkha troops were stationed there from 1948 (Rai, 2009, cited in Low, 2016:845). These Gurkhas were able to have their families with them in the married quarters of the military barracks in Hong Kong, but families were only allowed to stay with the Gurkhas for no more than three years, after which they had to return to Nepal (Law and Lee, 2013:997). As for the Gurkhas in Singapore, they 'are discouraged from integrating with the locals and are not allowed to marry Singaporean women' (Low, 2016:844). More interestingly, their wives and children are permitted to live in Singapore, but not allowed to seek employment there.

\subsection{Inequalities after the military service}

After the retirement, the Gurkhas will face two difficulties. One is the issue of settlement rights, for it is almost impossible for them to settle in the UK. And the other difficulty is that they have to restart a career to feed their families.

Before the reunification of Hong Kong to China in 1997, Hong Kong was a major settlement for the retired Gurkhas. Nonetheless, even in Hong Kong, they had to meet the challenge from the labor market and face the fact that they were more likely to be employed as security guards, bodyguards, drivers and the like. In other words, in Hong Kong both the Gurkha fathers and their children have to be engaged in physically related industries and taking low-paid jobs though the British government granted Hong Kong citizenship to approximately 7,000 Gurkha children, out of whom a substantial proportion had returned to Hong Kong to take up unskilled labor jobs (Yamanaka, 2000:70).

If the Gurkhas choose to continue their lives in other areas, they are more likely to move to the combat areas and join private security companies, for their 'fierce warrior' attribute founded in the martial race have offered them 'opportunities to continue to engage in labour outside their country' (Chisholm, 2014:31). For example, retired Gurkhas have been recruited by the Sultan of Brunei recruited for the country's security, thereby 'providing an avenue for what is known as a second career for these Gurkhas. About 2200 former Gurkha soldiers serve as the Sultan's security guards' (Yamanaka, 2000:69). Even working as security guards, they are confronted with discrimination. According to the interviews made by Amanda Chisholm, most of the white managers of the 
private security companies argued that Gurkhas were in good positions in the hierarchy of security contractors in Afghanistan. Though trained by the British and actually serving in the British army, the Gurkhas were more adaptable to the western cultures than the local Afghans, and were also able to communicate with the locals as well as the internationals in English, they were not equally treated as their white counterparts, because the managers believed that the white had more professional skills and cultural competencies than the Gurkhas, which leads to higher payment for the white in this filed (Chisholm, 2014:36). In other words, security companies know that Gurkhas are a real find, using the Gurkhas' name to attract clients but treating them differently not only in pay, but also in all the facilities like food and lodging. What is worse, it is believed that to achieve the Gurkhas' market value, they needed to be trained and commanded by the white experts.

\subsection{Inequalities in law \& British court}

The Gurkhas have been given low payment and pensions and experienced discrimination in terms of the settlement as well as recruitment, so they have recently decided to bring discrimination claims before the courts. As for the pensions, the court held that according to the terms of engagement, the Gurkhas should not be regarded as equal as the British soldiers, so their pensions as well as their payment should not be the same as those of the British. Besides, it is affirmed that when the Gurkhas retired and settled in their homeland, the living costs would be undoubtedly lower than those of the retired British soldiers living in Britain. Actually, it is unreasonable to determine the amount of pension according to the future settlement place, because both the British soldiers and the Gurkhas have devoted themselves to the military and deserve the same pension.

As for the settlement, there were more stringent rules for the Gurkhas who retired and planned to settle in Britain, so only few could really settle in Britain. For those who are on service, they are still Nepalese citizens, and their settlement right is also strictly limited in practice. Why did the British government formulate such rules? It is explained by the officials that if they made an open door settlement policy to the Gurkhas, they would not go back to Nepal with their income over years; instead, they would bring their families to Britain, which would have adverse effects on the economy, culture, religion and language of Nepal.

\section{Reasons for the Inequalities}

There are two main reasons that lead to the inequalities the Gurkhas have been confronted with in and after their service. One is the racial discrimination of the westerners against the Gurkhas, and the other is the colonial logics existing in the mind of the Gurkhas.

\subsection{Racial discrimination}

As is mentioned, the martial race theory has exerted negative influence on the recognition of the Gurkhas. They are irrationally considered to be not intellectual and dependent on the British. Therefore, the 'martial race' stereotype has contributed to the racial hierarchy in the British army, and the Gurkhas are placed in the lower positions. It is said that the Gurkhas have to be under the instruction of the British, so they only deserve lower payment; it is said that the Gurkhas need the assistance of the British commands, so they have little chance to be promoted in the army; it is said that the physical conditions of the Gurkhas are poorer than those of the white soldiers, so they have to retire at the best time of their lives, etc. Such latent racial discriminations have done great and long-lasting harm to Gurkhas.

\subsection{Colonial logics}

The colonial logics also result in their inequalities. Surprisingly, from the interviews made by Amanda Chisholm, it is obvious that the Gurkhas themselves have reinforced the logics. On the one hand, the Gurkhas have acknowledged the dominant role of the white soldiers in the private security industry, despite the fact that they have experienced more in international society and have gained rich communication skills. On the other hand, they have agreed that their identities are closely connected with the UK, and they need the assistance from the British military experts to train them to be professional soldiers from natural warriors. This subordinated identity has pushed them to the periphery in the position of static guard and convoy protection. Additionally, Gurkhas are proud of their martial history and Gurkha identity, claiming that these not only differentiate them from their Nepalese civilian counterparts, but also 'provide them with esteem and a sense of belonging'(Chisholm, 2014:35). In short, the expectations to be trained by the British military, the inseparable relationship with the British army, and the self-cognition of the Gurkhas are all deeply embedded in the colonial logics of the Gurkhas. Meantime, this kind of colonial legacy has prevented them from establishing their own identities in the international security markets, which has forced them to depend on the western private security company managers (Chisholm, 2014:367). 


\section{Ways to Eliminate Inequalities}

In order to eliminate the inequalities, both the Great Britain and the Gurkhas themselves need to take actions. The recent actions of the English courts have inadvertently led to discrimination, so it is necessary that intervention is needed to reform 'the institutional culture of discrimination that persists vis-à-vis the Gurkhas' (Kochhar-George, 2010:55). The only thing to note here is that the Gurkhas have regarded joining British army as not only a way to improve their financial situations but also an integral part of their identity formation, which means they want to continue their history of serving in British army. Therefore, three approaches can be taken by the British government: the first is to make some changes in the settlement policies of the Gurkhas. It is not possible to allow all the Gurkhas serving in the army to settle down in the UK, but priority to be settled in Britain should be given to those who have outstanding performances or those who are seriously injured in the military life. As for the rest of the Gurkhas, they need to be assessed by the fair and equal criteria, taking their contributions to the UK into consideration. Another approach is to liberalize the mobility in the chain of command. That is to say, the Gurkhas will not be limited to the Gurkha regiment, and they can be recruited into other regiments; there should also be growing opportunities for the Gurkha soldiers to be promoted as officers. With the mobility in the chain of command, the British soldiers as well as the commanders can learn more about the Gurkhas in reality, and can reduce the racial discrimination against the Gurkhas. The last approach is to extend the service time of the Gurkhas. To end racial discrimination, the Gurkhas should have the same service time in the army as the British soldiers. Hence, the Gurkhas do not necessarily feel uncertain and uneasy after their retirement in the prime of their lives. And it will be better if the outstanding ones can be kept in the army as instructors. Briefly speaking, what is most important for the British government is that they try to tackle the 'deep rooted issues of inequality' or to resolve 'longstanding issues of institutional discrimination'(Kochhar-George, 2010:44) out of their sincere concern for the Gurkhas and their families rather than out of the sympathy for their poverty or the 'pressure from the media, the general public and to a lesser extent the courts' (Kochhar-George, 2010:44).

From the individual level, many of the Gurkhas have realized their unstable and paradoxical nature of their identities, and regarded their participation in the private security industry as a short-term sacrifice to gain enough money to support their children's long-term education (Chisholm, 2014:39). So only with the help of education, can the Gurkha families live better lives in the future, even if the UK stops the recruitment of the Gurkhas. Moreover, providing chances for their children to get adequate and better education is a way not only to build their independent personalities, but also to help the Gurkhas to construct their motherland better. Therefore, to make a better Nepal, the Nepalese government has to create an atmosphere to help local people not only give up their idea of regarding a Gurkha as a source of pride for both the prestige and economic stability, but also change 'Nepal's culture of emigration where Nepalese young men follow their fathers' footsteps to become Gurkhas'(Low, 2016:846). That is to say, through the joint efforts of the Gurkh families and the government, the children of the Gurkha families will and can be able to avoid racial discrimination against them and get rid of their colonial logics through family education and social education.

\section{Conclusion}

The loyal and brave Gurkha regiment is a special part of the British army. With the small statures, they have been involved in the martial races surprisingly on account of their combat abilities, walking along their way to serve the British crown. However, the notions of martial races not only bring them opportunities to improve their financial situations, but also make them suffer from discrimination. During their service, they cannot get the same pay as the British, and even have little chance of being promoted. After the service at their best age, it is hard for them to be settled in the UK and they have to try their luck in the international security markets. However, the racial discourse as well as their inherent colonial logics make them subsidiary to the western soldiers- they cannot gain higher payment, nor can they be regarded as individuals. In this case, some measures need to be taken for the UK government, the Gurkhas themselves and the Nepalese government. In other words, the policies on mobility, settlements and the service time can be changed; meanwhile the Gurkhas need to change their traditional ideas, and try to create opportunities to send their children to get further and better education and the Nepalese government tries to develop its economy, thus creating an environment which can keep its people and make them live and work happily in their motherland instead of turning a blind eye to their lives or even regarding their making a living outside as a best solution to domestic problems.

\section{Acknowledgements}

I am grateful first to my teacher of the course Security and Development in the University of Queensland, then to my parents for their encouragements in my writing and finally to the reviewers for their acceptance of the paper 
and suggestions for the paper revision.

\section{References}

Chisholm, A. (2014). Marketing the Gurkha security package: Colonial histories and neoliberal economies of private security. Security Dialogue, 45(4), 349-372. https://doi.org/10.1177/0967010614535832

Chisholm, A. (2014). The silenced and indispensible Gurkhas in private military security companies. International Feminist Journal of Politics, 16(1), 26-47. https://doi.org/10.1080/14616742.2013.781441

Eichler, M. (2014). Citizenship and the contracting out of military work: from national conscription to globalized recruitment. Citizenship Studies, 18(18), 600-614. https://doi.org/10.1080/13621025.2013.865904

Golay, B. (2006). Rethinking Gorkha identity: outside the imperium of discourse, hegemony and history. Peace and Democracy in South Asia, 2(1\$2), 23-49

Kochhar-George, C. S. (2010). Nepalese Gurkhas and their battle for equal rights. Race \& Class, 52(2), 43-61. https://doi.org/10.1177/0306396810379073

Law, K.-Y., \& Lee, K.-M. (2013). Socio-political Embeddings of South Asian Ethnic Minorities' Economic Situations in Hong Kong. Journal of Contemporary China, 22(84), 984-1005. https://doi.org/10.1080/10670564.2013.795312

Low, K. (2016). Migrant warriors and transnational lives: constructing a Gurkha diaspora. Ethnic and Racial Studies, 39(5), 840-857. https://doi.org/10.1080/01419870.2015.1080377

Rand, G. (2006). 'Martial Races' and 'Imperial Subjects': Violence and Governance in Colonial India, 1857-1914. European Review of History, 13(1), 1-20. https://doi.org/10.1080/13507480600586726

Yamanaka, K. (2000). Nepalese Labor Migration to Japan: From Global Warriors to Global Workers. Ethnic and Racial Studies, 23(1), 62-93. https://doi.org/10.1080/014198700329132

\section{Copyrights}

Copyright for this article is retained by the author(s), with first publication rights granted to the journal.

This is an open-access article distributed under the terms and conditions of the Creative Commons Attribution license (http://creativecommons.org/licenses/by/4.0/). 